\title{
New species of Leptophlebiidae (Ephemeroptera) from Mexico and Central America
}

\author{
C. R. Lugo-Ortiz 1 \\ W. P. McCafferty 1
}

Keywords : Ephemeroptera, Leptophlebiidae, Mexico, Central America, new species, new records.

Eleven new species in the mayfly family Leptophlebiidae are described from larvae from Mexico and Central America. Choroterpes ungulus, n. sp., Thraulodes eccentricus [=Allen and Brusca's Thraulodes sp. B], n. sp., and Thraulodes tenuli- neus [=Allen and Brusca's Thraulodes sp. D], n. sp., are described from Mexico; Farrodes otiesa, n. sp., Hagenulopsis ingens, n. sp., Hagenulopsis ramosa, n. sp., Terpides diadema, n. sp., Traverella holzenthali, n. sp., and Traverella longifrons [=Allen's Traverella sp. B], n. sp., are described from Costa Rica; Traverella promifrons [=Allen's Traverella sp. C], n. sp., is described from Belize and Costa Rica; and Thraulodes grandis, n. sp., is described from Guatemala.

\section{Espèces nouvelles de Leptophlebiidae (Ephemeroptera) du Mexique et d'Amérique Centrale}

Mots clés : Ephemeroptera, Leptophlebiidae, Mexique, Amérique Céntrale, espèces nouvelles, citations nouvelles.

Onze espèces nouvelies de la famille des Leptophlebiidae sont décrites à partir de larves provenant du Mexique et d'Amérique Centrale. Choroterpes ungulus, n. sp., Thraulodes eccentricus [=Allen et Brusca's Thraulodes sp. B], n. sp., and Thraulodes tenulineus [=Allen et Brusca's Thraulodes sp. D], n. sp., sont décrites du Mexique; Farrodes otiesa, n. sp., Hagenulopsis ingens, n. sp., Hagenulopsis ramosa, n. sp., Terpides diadema, n. sp., Traverella holzenthali, n. sp., et Traverella longifrons [=Allen's Traverella sp. B], n. sp., sont décrites de Costa Rica; Traverella promifrons [=Allen's Traverella sp. C], n. sp., est décrite de Bélize et de Costa Rica; et Thraulodes grandis, n. sp.; est décrite du Guatémala.

\section{Introduction}

The mayfly family Leptophlebiidae is a relatively poorly-known, albeit integral, component of stream ecosystems in Mexico and Central America (Edmunds et al. 1976, Flowers 1992). Only 29 nominal species in Atopophlebia Flowers, Choroterpes Eaton, Hydrosmilodon Flowers and Domínguez, Neochoroterpes Allen, Paraleptophlebia Lestage, Terpides Demoulin, and Thraulodes Ulmer are known from the region. Farrodes Peters and Hagenulopsis Ulmer have been reported from the region (Edmunds et al. 1976, Davis 1987, Flowers 1991, 1992), but no species belonging

1. Department of Entomology, Purdue University, West Lafayette, IN 47907, USA. to them have been formally described. Other reports of species assigned to Choroterpes, Hermanella Needham and Murphy, Hermanellopsis Demoulin, Homothraulus Demoulin, Thraulus Eaton, and Ulmeritus Traver are probably incorrecty classified according to Peters (1988) and McCafferty et al. (1992). Of the total number of species, 15 are known from larvae and adults and 14 from adults only.

We describe eleven new species in Choroterpes, Farrodes, Hagenulopsis, Terpides, Thraulodes, and Traverella based on larvae collected from Mexico and Central America. We maintain that the description of these larvae, even though associated adults remain unknown, is of timely necessity because of their endangerment. Freshwater habitats are being degraded and destroyed at an accelerated rate in the region (Faber 1993), and species must be documented before they potentially disappear (Wheeler 1990). The description of larvae is also of practical value to freshwater biologists and water quality assessors in the region because they mainly collect and work with this life sta- 
ge and generally do not rear and identify adults. Thus, biodiversity assessment, which serves the cause to conserve not only the species themselves but freshwater ecosystems in the region, supersedes the idealized philosophy of describing new species of Leptophlebiidae only if they are known as adults, and the impracticality of waiting indefinitely for all previously known species to be reared.

The materials that formed the basis of this study are housed at Florida A\&M University (FAMU), Tallahassee, Florida; Instituto de Ecología, A. C. (IEAC), Veracruz, México; Purdue Entomological Research Collection (PERC), West Lafayette, Indiana; and the Universidad Nacional Autónoma de México (UNAM), México, D. F.

\section{Choroterpes ungulus, n. sp.}

\section{Mature larva}

Body : length $5.2 \mathrm{~mm}$. Caudal filaments : length unknown. General coloration yellow-brown.

Head : Coloration yellow-brown. Area between ocelli with broad dark band. Vertex suffused with black. Antennae pale yellow-brown, about 2.0x length of head capsule. Labrum (Fig. 1) yellowish, with anteromedial emargination ; two submarginal anteromedial rows of long, simple setae present ; very fine simple setae scattered dorsally and marginally. Hypopharynx yellowish, with numerous setae along lateral margin. Right mandible (Fig. 2) yellowish, with 10-12 long, simple setae marginally ; basal set of incisors with three denticles, distal set with two denticles ; prostheca with long, fine, simple setae almost extending as far as mola. Left mandible (Fig. 3) yellowish, with 1012 long, simple setae marginally; basal set of incisors with apparently two fused denticles, distal set with three denticles ; prostheca with robuist process and long, fine simple setae almost extending as far as mola. Maxillae (Fig. 4) yellowish, with palps four segmented ; palp segment 1 very short; almost imperceptible ; segments 2 and 3 robust, with sparse, long; fine, simple setae ; palp segment 4 pointed, with numerous long, fine, simple setae; galealaciniae with very dense tuft of rust-colored, simple setae, intermixed with pectinate setae, and with long row of long, simple setae medially. Labium (Fig. 5) yellowish, with palps three segmented ; palp segment 1 robust; with 15-16 long setae laterally and 13-14 long setae medially ; segment 2 less robust than segment 1 , with seven to eight long, simple setae in distal half of medial margin, and many long, fine, simple setae on lateral margin segment 3 pointed, with four to five long, simple setae medially, two long, robust, simple setae dorsally, and many long, fine setae laterally, becoming more numerous apically ; glossae with dense tuft of short, robust, simple setae distally ; paraglossae with long, fine setae dorsally.

Thorax : Coloration pale yellow-brown to pale brown. Pronotum suffused with black markings laterally. Sterna pale yellow-brown. Midleg pale yellowbrown, with medial and submedial black markings on anterior face of femur ; claw with eight denticles.

Abdomen : Coloration yellow-brown, with complex pattern (Fig. 6). Terga 1-7 with pale yellow-brown median streak and large sublateral spots; tergum 8 with pale yellow-brown posterior triangular marking and large sublateral spots; tergum 9 with pale yellowbrown median streak and large sublateral spots ; tergum 10 lightly suffused with small black spots. Sterna pale yellow-brown. Gill 1 (Fig. 7) elongate, simple, and slender. Gills 2-7 well tracheated ; medial process of outer lamella relatively broad, with bluntly pointed apex (Fig. 8) ; medial process of inner lamella spear-like (Fig. 9).

\section{Material examined}

Holotype : Female larva, MEXICO, Chiapas Sta., $\mathrm{km} 15$ carretera hacia Bejucos, ca Altamirano, XI-221984, Brailovsky et al., deposited at UNAM.

\section{Etymology}

The specific epithet is based on the Latin word ungulus. It is an allusion to the pale round marks on the terga.

\section{Discussion}

The specimen on which the above description is based is an ultimate larval instar beginning to molt. That it represents a new species is shown by its distinctive abdominal color pattern (Fig. 6) and the shape of the outer lamellae of gills 2-7 (Fig. 8).

\section{Farrodes otiesa, n. sp.}

\section{Mature larva}

Body : length $6.0-7.5 \mathrm{~mm}$. Caudal filaments : length 8.5-9.0 mm. General coloration dark yellow-brown.

Head : Coloration medium brown (Fig. 10). Area between compound eyes and antennae suffused with black. Area between compound eyes and lateral ocelli with pale yellow mark. Pale yellow triangular mark below medial ocellus. Compound eyes of males redbrown. Vertex lightly suffused with black in females ; markings absent in males. Antennae pale brown to pale yellow, scapes sometimes distally medium brown, 3.0-3.5x length of head capsule. Labrum as in Figure 176 and 177 of Peters (1971). Hypopharynx as in Figure 157 of Peters (1971). Left mandible as in Figure 


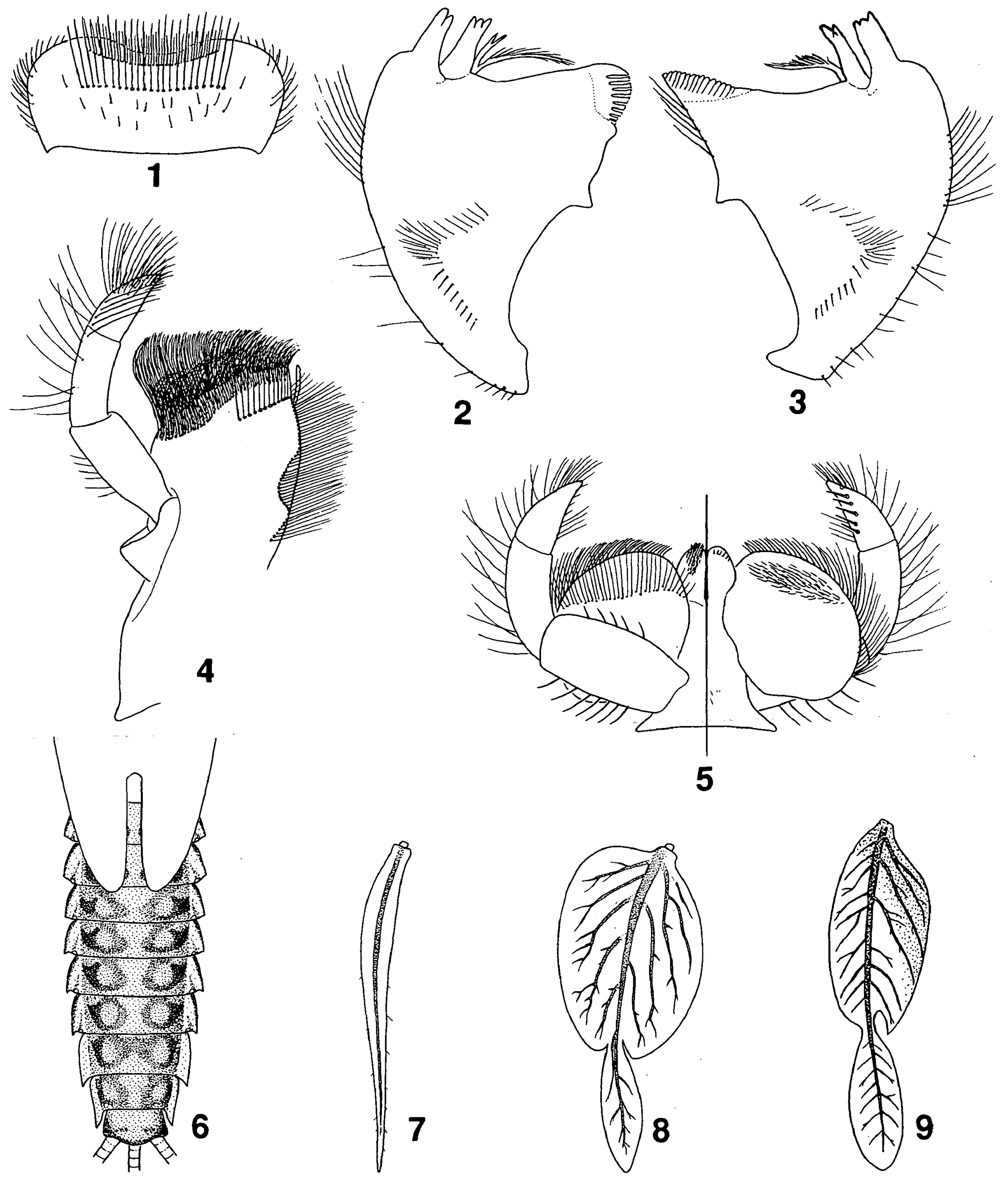

Fig. 1-9. Choroterpes ungulus, n. sp., mature larva. $1:$ labrum (dorsal). $2:$ left mandible. $3:$ right mandible. $4:$ right maxilla. $5:$ labium (leftventral; right-dorsal). $6:$ abdomen (dorsal). $7:$ gill $1.8:$ gill 4 (outer lamella). $9:$ gill 4 (inner lamella).

Fig. 1-9. Choroterpes ungulus, n. sp., larve au dernier stade. $1:$ labre (vue dorsale), $2:$ mandibule gauche. $3:$ mandibule droite. $4:$ maxille droite. 5 : labium (vue ventrale à gauche; vue dorsale à droite). $6:$ abdomen (vue dorsale). $7:$ le branchie. $8: 4$ e branchie (lamelle externe). $9: 4 \mathrm{e}$ branchie (lamelle interne). 


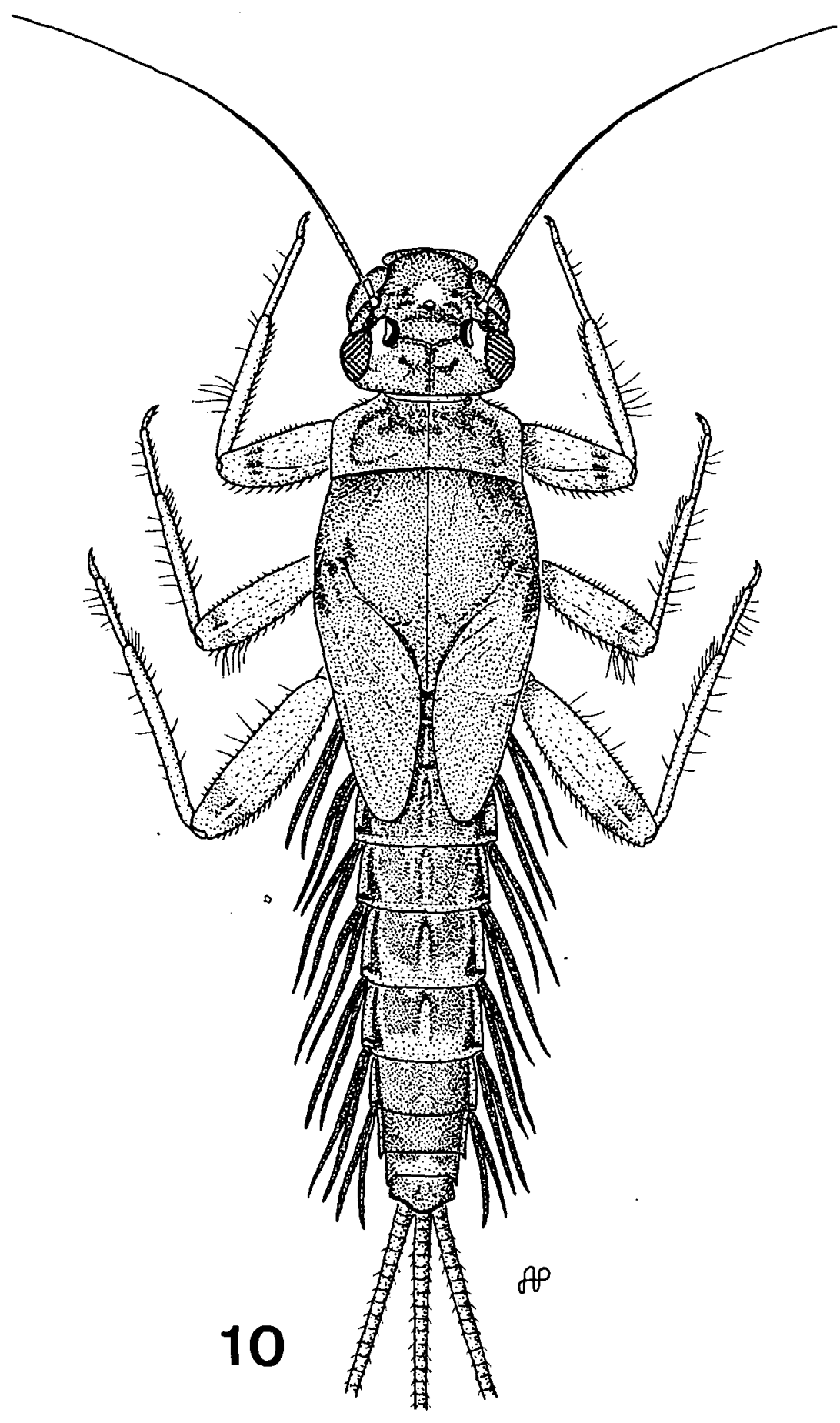

Fig. 10. Farrodes otiesa, n. sp., mature larva (dorsal).

Fig. 10. Farrodes otiesa, n. sp., larve au demier stade (vue dorsale).

166 of Peters (1971). Maxillae as in Figure 148 of Peters (1971). Labium as Figure 139 of Petersi'(1971).

Thorax : Coloration medium brown (Fig. 10). Pronotum suffused with black, with five to eight simple setae anteromedially. Meso- and metanotum medium brown. Forewingpads with conspicuous crease in midregion. Sterna pale brown. Pleura suffused with black. Legs pale brown; anterior faces of coxae and trochanters with five to six small simple setae ; femora with many long, simple setae dorsally, with short and long, simple setae ventrally, and with long, simple setae on anterior and posterior faces ; tibiae with numerous fine, short, simple setae ventrally (some setae branched), and with scattered long, fine, simple setae dorsally (branched setae more abundant on foretibiae) ; tarsi with row of short, simple setae ventrally and scattered long, fine, simple setae dorsally ; tarsal claws as in Figure 197 of Peters (1971), with 10-11 conspicuous denticles distally and 7-10 minute denticles proximally (distal denticle largest).

Abdomen : Coloration medium brown (Fig. 10). Female terga 1-8 suffused with black, with medial pale brown streak and two anterior submedial pale brown spots, with black lateral streaks; tergum 9 anteriorly suffused with black and posteriorly pale brown, sometimes completely pale brown; tergum 10 pale brown. Male tergum 1 suffused with black ; terga 2-6 pale brown with black lateral and dorsal margins ; terga 7-8 suffused with black, with pale brown medial streak and posterior margins ; tergum 9 anteriorly suffused with black and posteriorly pale brown; tergum 10 pale brown. Caudal filaments pale brown to yellow-brown.

\section{Material examined}

Holotype : Female larva, COSTA RICA, Guanacaste Prov., Río Tenorio at Finca La Pacífica, E of Panamerican Hwy, II-2-1969, W. P. McCafferty, deposited at PERC. Paratypes: Two female larvae and one male larva, same data and deposition as holotype ; seven female and four male larvae, COSTA RICA, San José Prov., Río Parrita Chiquito, Rt 12, $6.5 \mathrm{~km} \mathrm{SW}$ jct Rt 2, $9.703^{\circ} \mathrm{N} / 83.970^{\circ} \mathrm{W}, 1990 \mathrm{~m}, \mathrm{IV}-10-1987$, Holzenthal, Hamilton, and Heyn, deposited at FAMU.

Additional material examined: Two female and one male larvae, same data and deposition as holotype ; four female larvae, COSTA RICA, Heredia Prov., Quebrada Salto, in SW area of teaching area at La Selva, II-25-1969, W. P. McCafferty, deposited at PERC; four female and five male larvae, COSTA RICA, Puntarenas Prov., $10 \mathrm{~km} \mathrm{~N}$ of San Vito, at quarry waterfall, III-16-1969, W. P. McCafferty, deposited at PERC.

\section{Etymology}

The specific epithet is an arbitrary combination of letters forming a phonetic allusion to OTS (Organization for Tropical Studies), which provided support funds to this paper's second author in 1969 when he discovered this species in Costa Rica.

\section{Discussion}

Farrodes otiesa is common in a variety of erosional biotopes in small to large stream in both dry and wet forest areas in Costa Rica. The color pattern of the species is superficially similar to $F$. texanus. It differs 
from that species in its relatively large size, its longer antennae, the absence of a median pale yellow mark on the vertex, the presence of a conspicuous crease in the forewingpads, its slender tarsi, and the absence of transverse basal and subapical brown bands on the tarsi (Fig. 10).

\section{Hagenulopsis ingens, n. sp.}

\section{Mature larva}

Body : length $8.0-9.2 \mathrm{~mm}$. Caudal filaments : length unknown. General coloration dark yellow-brown to orange-brown.

Head : Coloration yellow-brown. Frons and vertex dark yellow-brown to medium brown. Antennae pale, 2.0-2.3x length of head capsule ; scapes yellow-brown ; pedicel suffused with black. Labrum (Figs. 11, 12) with anteromedial emargination with three denticles; two submarginal anteromedial rows of simple setae present ; very fine, simple setae scattered dorsally and marginally. Hypopharynx (Fig. 13) with anterior margin of lingua deeply cleft and with two curved lateral processes ; superlinguae with numerous long, simple setae. Right mandible (Fig. 14) with basal set of incisors having two denticles and three to four short, simple setae laterally, and with distal set of incisors having three denticles. Left mandible (Fig. 15) with basal and distal sets of incisors with three denticles each, and with distal set appearing serrate laterally ; prostheca with long, simple setae extending towards mola. Both mandibles with scattered fine, simple setae laterally. Maxillae (Fig. 16) with palps four segmented; palp segment 1 very short, almost imperceptible; segments 2 and 3 with sparse long, fine, simple setae ; segment 4 pointed, with numerous long, fine, simple setae on surface ; galealacinia with very dense tuft of rust-colored simple setae intermixed with pectinate setae distally, and with long row of fine, simple setae medially. Labium (Fig. 17) with palps three segmented ; palp segment 1 robust, with 15-16 long setae laterally and 1314 long setae medially; segment 2 less robust than segment 1 , with seven to eight long, simple setae in distal half of medial margin, and many long, fine, simple setae on lateral margin ; segment 3 pointed, with four to five long, simple setae medially, two long, robust, simple setae dorsally, and many long, fine setae laterally, becoming more numerous apically ; glossae with dense tuft of short, robust, simple setae distally ; paraglossae with long, fine setae dorsally.

Thorax : Coloration medium brown to yellowbrown. Pronotum marginally suffused with black; two black triangular submedian marks anteriorly ; mesonotum suffused with black anterolaterally, becoming yel- low-brown towards wingpads ; metanotum medium brown. Sterna medium brown to pale brown. Hindwingpads absent. Forefemora yellow-brown, with many long, simple setae dorsally (distal setae longer) and shorter simple setae ventrally (more conspicuous distally) ; foretibiae yellow-brown, with numerous branched setae ventrally and sparse long, fine setae dorsally ; foretarsi with six to seven short, simple setae ventrally and sparse long, fine setae dorsally ; foretarsal claw with 11-12 denticles, distal denticle very large. Midlegs similar to forelegs, except tibiae with 10-11 simple setae of medium length ventrally. Hindfemora with many simple setae of varying lengths dorsally and short, acute setae ventrally ; hindtibiae medium brown, with simple setae of medium length on anterior and posterior surfaces and long, simple setae distally on posterior surface (Fig. 18) ; hindtarsi with seven setae increasing in length and width distally on ventral margin, dorsal margin with sparse long, fine simple setae ; hindtarsal claws with 13-15 denticles increasing in length distally, distal denticle larger.

Abdomen : Coloration orange-brown to dark yellow-brown, margins yellow-brown. Terga 1-2 yellowbrown or medium brown, 3-8 orange-brown to dark yellow-brown, terga 9-10 dark brown. Sterna dark yellow-brown to medium brown and with medium brown posterior band ; sterna 7-9 darker than preceding sterna. Sternum 10 deeply cleft medially. Segment 10 with posterolateral projections. Gills (Fig. 19) 1-7 deeply cleft, long, and slender. Caudal filaments basally dark brown, apparently becoming paler distally.

\section{Material examined}

Holotype : Female larva, COSTA RICA, Cartago Prov., Reserva Tapanti, Río Badilla, $9.688^{\circ} \mathrm{N} / 83.757^{\circ} \mathrm{W}$, III-21-1987, $1640 \mathrm{~m}$, Holzenthal and Hamilton, deposited at FAMU. Paratypes : Female larva, same data as holotype, deposited at PERC. Additional material examined: Two female larvae, COSTA RICA, San José Prov., Parque Nacional Braulio Carrillo, Río Zurqui, $10.059^{\circ} \mathrm{N} / 84.019^{\circ} \mathrm{W}, 1650 \mathrm{~m}$, VIII-6-1986, Holzenthal, Heyn, and Armitage, deposited at FAMU and PERC.

\section{Etymology}

The specific epithet is a Latin word meaning large and is in reference to the relatively large size of the larva.

\section{Discussion}

Hagenulopsis ingens and $H$. ramosa (see below) are generally similar ; however, three diagnostic specific features are associated with $H$. ingens: the presence of simple setae posterodistally on the hindtibiae (Fig. 18), 


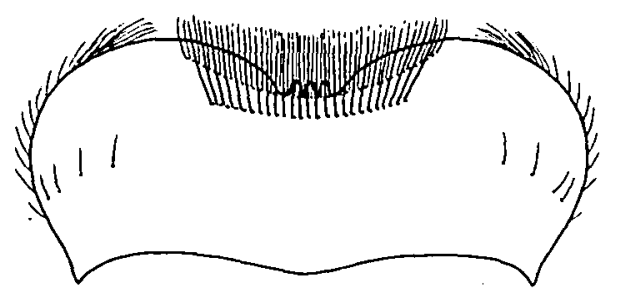

11

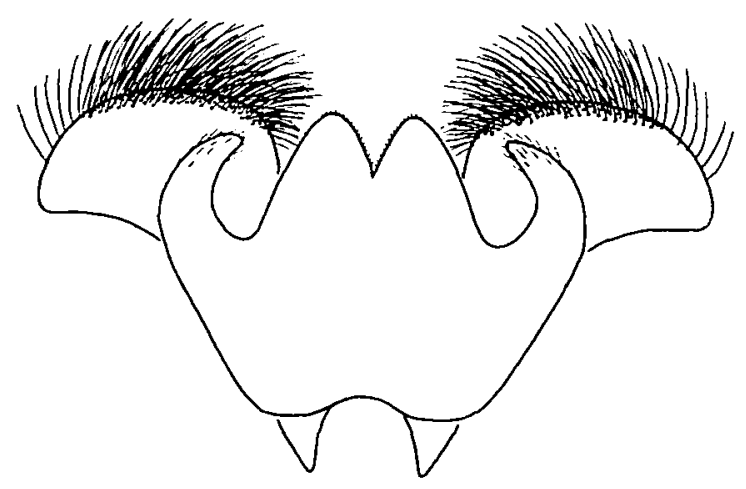

13

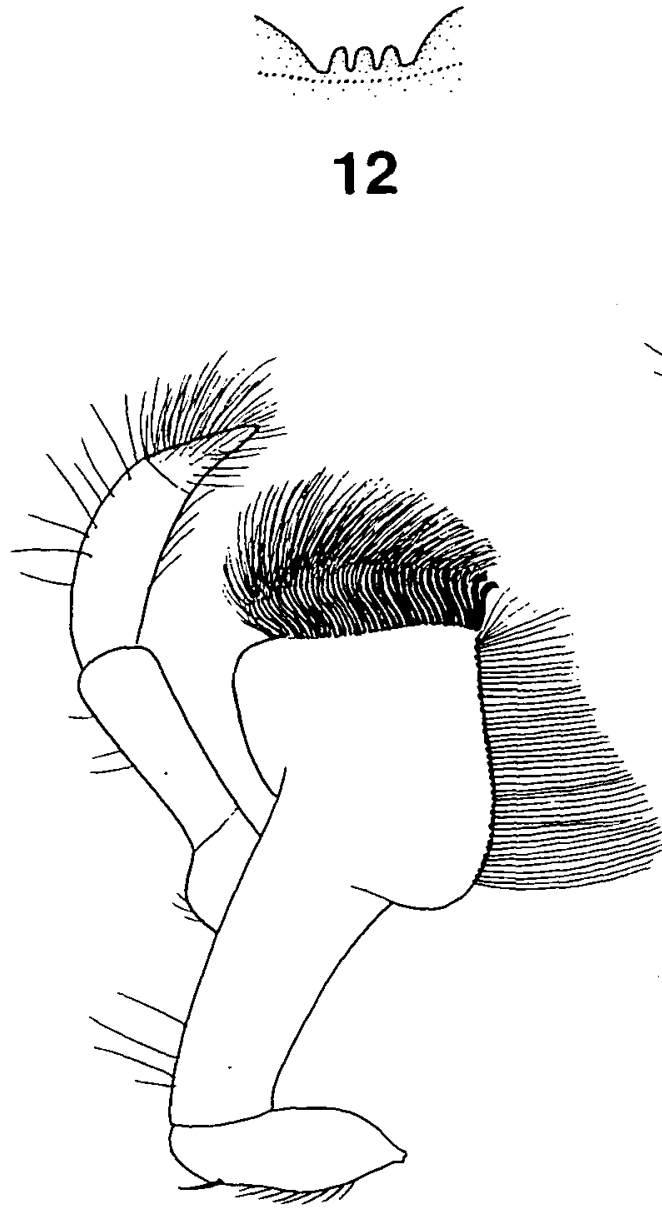

16

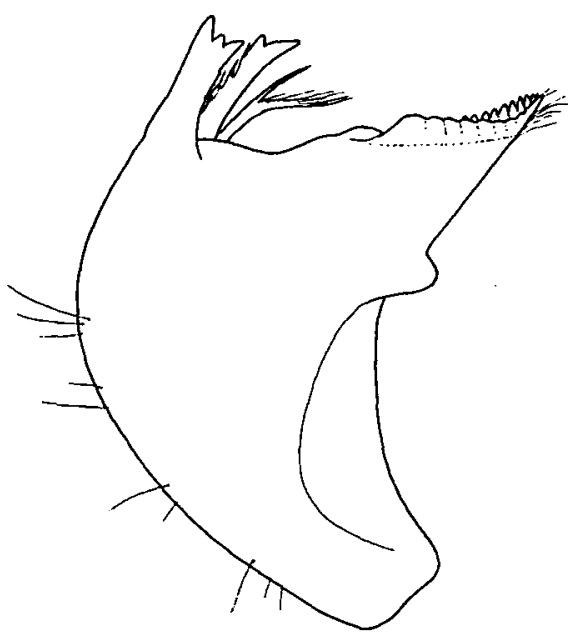

14

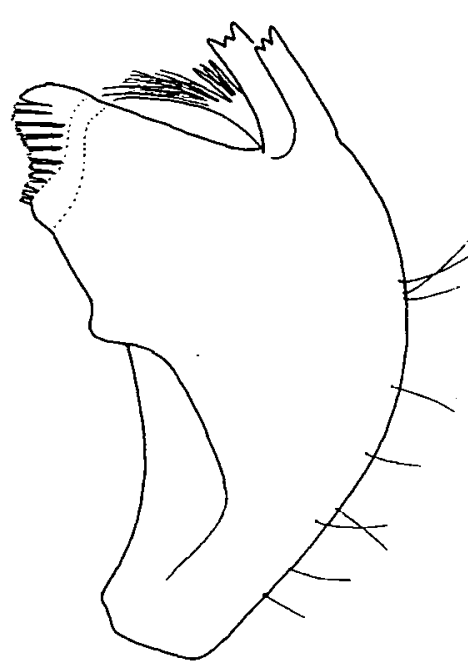

15

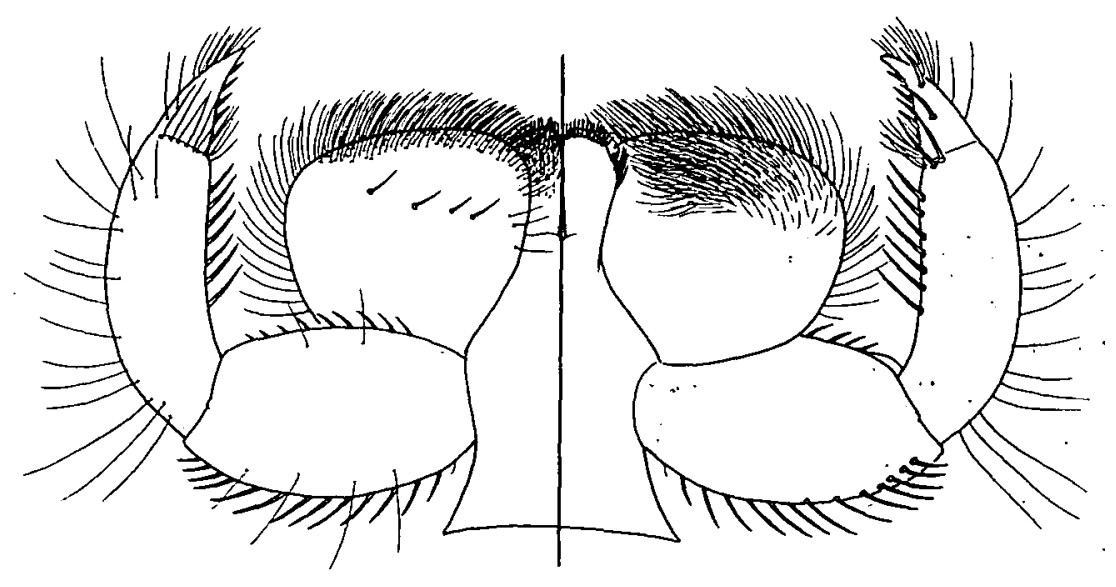

17

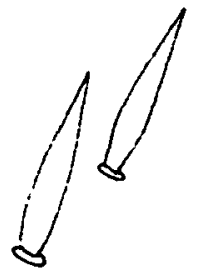

18

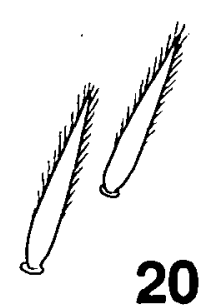

Fig. 11-20. Hagenulopsis spp., mature larvae. $11: H$. ingens, n. sp., labrum (dorsal). $12: H$. ingens, $\mathrm{n}$. sp., detail of anteromedial emargination of labrum (dorsal). $13: H$. ingens, n. sp., hypopharynx. $14: H$. ingens, n. sp., right mandible. $15: H$. ingens, n. sp., left mandible. $16: H$. ingens, n. sp., right maxilla. $17: H$. ingens, n. sp., labium. $18: H$. ingens, n. sp., posterolateral setae of hindfemora. $19: H$. ingens, n. sp., gill 4 . $20: H$. ramosa, $\mathrm{n}$. sp., posterodistal setae of hindfemora.

Fig. 11-20. Hagenulopsis spp., larve au dernier stade (vue dorsale). $11: H$. ingens, n. sp., labre (vue dorsale). $12: H$. ingens, n. sp., détail de l'émargination médiane antérieure du labre (vue dorsale). $13: H$. ingens, n. sp., hypopharynx. $14: H$. ingens, n. sp., mandibule droite. $15: H$. ingens, n. sp., mandibule gauche. $16: H$. ingens, n. sp., maxille droite. $17: H$. ingens, n. sp., labium. $18: H$. ingens, n. sp., soies postérolatérales des fémurs postérieurs. $19: H$. ingens, n. sp., 4e branchie. $20: H$. ramosa,'n. sp., soies postérodistales des fémurs postérieurs. 
a relative larger body size, and the presence of scattered long, fine setae over the entire body.

\section{Hagenulopsis ramosa, n. sp.}

\section{Mature larva}

Body : length 7.0-7.2 mm. Caudal filaments : length 8.0-9.0 mm. General coloration glossy medium brown.

Head : Coloration glossy medium brown; frons and vertex dark brown; area surrounding compound eyes pale yellow. Antennae pale, 2.3-2.5x longer than head capsule. Labrum (as in Figs. 11, 12) with anteromedial emargination with three denticles ; two submarginal anteromedial rows of simple setae present ; very fine, simple setae scattered dorsally and marginally. Hypopharynx (as in Fig. 13) with anterior margin of lingua deeply cleft and with two curved lateral processes ; superlinguae with numerous long, simple setae. Right mandible (as in Fig. 14) with basal set of incisors with two denticles and three to four short, simple setae laterally, distal set with three denticles. Left mandible (as in Fig. 15) with basal and distal sets of incisors with three denticles each, and distal set appearing serrate along lateral margin ; prostheca with long, simple setae extending towards mola. Both mandibles with scattered fine, simple setae laterally. Maxillae (as in Fig. 16) with palps four segmented; palp segment 1 very short, almost imperceptible; segments 2 and 3 with sparse long, fine, simple setae ; segment 4 pointed, with numerous long, fine, simple setae on surface ; galealacinia with very dense tuft of rust-colored, simple setae intermixed with pectinate setae distally, and with long row of long, simple setae medially. Labium (as in Fig. 17) with palps three segmented ; palp segment 1 robust, with 15-16 long setae laterally and 13-14 long setae medially ; segment 2 less robust than segment 1 , with seven to eight long, simple setae in distal half of medial margin, and many long, fine, simple setae on lateral margin ; segment 3 pointed, with four to five long, simple setae medially, two long, robust, simple setae dorsally, and many long, fine setae laterally, becoming more numerous apically ; glossae with dense tuft of short, robust, simple setae distally; paraglossae with long, fine setae dorsally.

Thorax : Coloration glossy medium brown, with no distinct color pattern. Sterna glossy gray-brown. Hindwingpads absent. Forefemora with many long, simple setae dorsally (distal setae longer) and shorter simple setae ventrally (more conspicuous distally); foretibiae with numerous branched setae ventrally and sparse long, fine, simple setae dorsally, and black distal band ; foretarsi with six to seven short, simple setae ventrally, sparse long, fine setae dorsally ; foretarsal claws with 11-12 denticles, distal denticle very large. Midlegs similar to forelegs, except tibiae with 10-11 simple setae of medium length ventrally. Hindfemora suffused with black spots ventrally and distally, with many simple setae of varying lengths dorsally, and with short, acute, simple setae ventrally; hindtibiae with simple setae of medium length scattered over anterior and posterior surfaces and long, branched setae distally on posterior surface (Fig. 20); hindtarsi with seven simple setae increasing in length and width distally on ventral margin, dorsal margin with sparse, very long, fine, simple setae ; hindtarsal claws with 13-15 denticles increasing in length distally, distal denticle larger.

Abdomen : Coloration glossy medium brown, with no distinct pattern. Sterna glossy yellow-brown to glossy gray-brown, gradually becoming medium brown on distal segments. Sternum 10 deeply cleft medially. Segment 10 with posterolateral projections. Gil1s 1-7 deeply cleft, long, and slender (as in Fig. 19). Caudal filaments medium brown proximally, becoming yellow-brown distally; terminal filament longer than cerci.

\section{Material examined}

Holotype : Female larva, COSTA RICA, Puntarenas Prov., Río Guineal, nr $1 \mathrm{~km}$ (air) E of Finca Helechales, $840 \mathrm{~m}, 9.076^{\circ} \mathrm{N} / 83.092^{\circ} \mathrm{W}$, II-22-1986, Holzenthal, Morse, and Fasth, deposited at FAMU. Paratype: One female larva, same data as holotype, deposited at PERC.

\section{Etymology}

The specific epithet is a derivation of the Latin word ramus, meaning branch. It is an allusion to the distinguishing branched setae on the distal end of the hindtibiae.

\section{Discussion}

Hagenulopsis ramosa can be distinguished from $H$. ingens (see above) by the presence of branched setae on the distal end of the hindtibiae (Fig. 20), the relatively fewer long, fine, simple setae over the body, and the somewhat smaller body size.

\section{Terpides diadema, n. sp.}

\section{Mature larva}

Body : length $8.0 \mathrm{~mm}$. Caudal filaments : length unknown. General coloration yellow-brown.

Head : Coloration pale yellow-brown, somewhat darker on vertex ; blackish mark in form of triangle between ocelli. Antennae pale yellow. Clypeus with scattered fine, simple setae. Labrum (Fig. 21) yellowish, 
with anteromedial emargination with six poorly defined denticles ; submarginal row of long, simple setae present ; long, fine, simple setae scattered dorsally and anteriorly. Hypopharynx as in Figure 22. Mandibles yellowish, robust as in Figures 23 and 24. Maxillae (Fig. 25) yellowish, with galealaciniae with apical tuft of simple setae and six to eight pectinate setae ; palps four segmented, extending beyond galealacinia, segment 1 small and almost imperceptible, segments 2-4 subequal in length and bearing scattered fine, simple setae. Labium (Fig. 26) yellowish, with three-segmented palps ; palp segment 1 very robust and with 15-18 long, simple setae laterally and scattered fine, simple setae medially; segment 2 slender in comparison to segment 1 , with 16-18 very fine, long, simple setae laterally and three fine, long, simple setae distally on medial margin ; segment 3 with 13-15 long, fine, simple setae dorsally and numerous stout, short, simple setae medially, becoming more concentrated distally, and eight to nine long, fine, simple setae along anterior margin ; glossae and paraglossae with numerous fine, long, simple setae scattered dorsally and ventrally.

Thorax : Coloration pale yellow-brown to medium yellow-brown. Pronotum with complex faint color pattern and very short, simple setae on anterolateral margin ; meso- and metanotum with no distinct color pattern. Sterna pale yellow-brown. Legs pale yellowbrown ; forefemora with row of 22 short, stout, simple setae ventrally (giving femora serrate appearance), with seven to eight long, simple setae dorsally and five to six long, simple setae anterodorsally ; foretibiae bare dorsally except for very fine, long, simple setae, ventral margin with many scattered short, stout, simple setae, becoming longer and somewhat dense distally ; foretarsi with two rows of 14-16 long, simple setae ventrally, dorsal margin bare except for very fine, long setae ; foretarsal claws with seven to eight denticles, median denticle larger than others ; mid- and hindlegs similar to forelegs except anterior face of femora with scattered short, stout, simple setae and tibiae with short, stout, simple setae dorsally.

Abdomen : Coloration yellow-brown to medium brown, with complex pattern (Fig. 27). Tergum 1 brown; terga 2-4 with pale median and sublateral spots ; tergum 5 with pale sublateral spots, median spot almost imperceptible ; terga 6-7 with crown-like median pale yellow markings ; tergum 8 with V-shaped medium brown mark ; and terga 9-10 yellow-brown. Tergal margins pale except for darker gill bases. Small posterolateral projections on terga 8-9. Gills (Fig. 28) long, almost as long as three abdominal segments. Caudal filaments medium brown basally.

\section{Material examined}

Holotype : Female larva, COSTA RICA, Puntarenas Prov., Río Sinigri, nr $2 \mathrm{~km}$ (air) S of Finca Helechales, $9.057^{\circ} \mathrm{N} / 83.082^{\circ} \mathrm{W}, 720 \mathrm{~m}$, II-21-1986, Holzenthal, Morse, and Fasth, deposited at FAMU.

\section{Etymology}

The specific epithet is a Latin noun, used in apposition, meaning crown. It refers to the crown-like markings of the abdomen.

\section{Discussion}

The description of $T$. diadema is based on a single female specimen ; however, its striking abdominal pattern (Fig. 27) and large size show that it is specifically distinct and allow it to be easily told from $T$. jessiae Peters and Harrison.

\section{Thraulodes eccentricus, n. sp.}

Thraulodes sp. B Allen and Brusca 1978 : 418.

\section{Mature larva}

Body : length 6.7-8.0 mm. Caudal filaments : length 9.0-11.0 $\mathrm{mm}$. General body coloration yellow-brown and reddish.

Head : Coloration pale yellow. Area between ocelli with V-shaped black band. Turbinate eyes in males pale yellow. Antennae pale, 2.0-2.3x length of head capsule. Clypeus anteriorly suffused with black. Labrum heavily suffused with black dorsally, with two long rows of simple setae above anteromedial emargination and with fine, simple setae scattered dorsally and marginally ; anteromedial emargination with two long denticles and one very small denticle. Hypopharynx suffused with black, especially along exterior margin of superlinguae ; lingua with long, curved lateral processes, and medial emargination interrupted by medial hump ; superlinguae with numerous long, simple setae along exterior margin. Right mandible suffused with black dorsally; row of fine, simple setae extending from middle portion of lateral margin to base of outer incisors ; basal and distal sets of incisors with three denticles. Left mandible same as right mandible. Maxillae suffused with black laterally; galealacinia with very dense tuft of rust colored, simple setae and 15-18 long, pectinate setae submarginally on anterolateral area of ventral surface ; maxillary palps four segmented, with very long, fine, simple setae scattered along lateral margin ; palp segment 1 very small, entirely suffused with black; segment 2 basally suffused with black; segments 3 and 4 pale ; segment 4 pointed, with numerous fine, simple setae distolaterally. Labium with glossae and paraglossae covered with nu- 


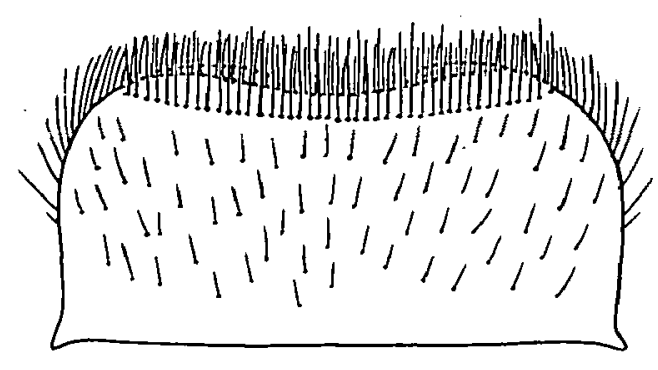

21

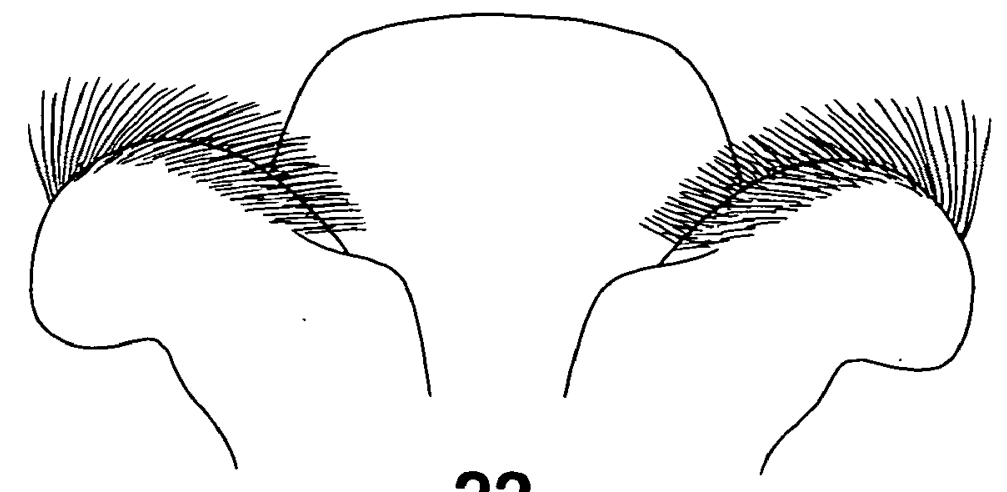

22

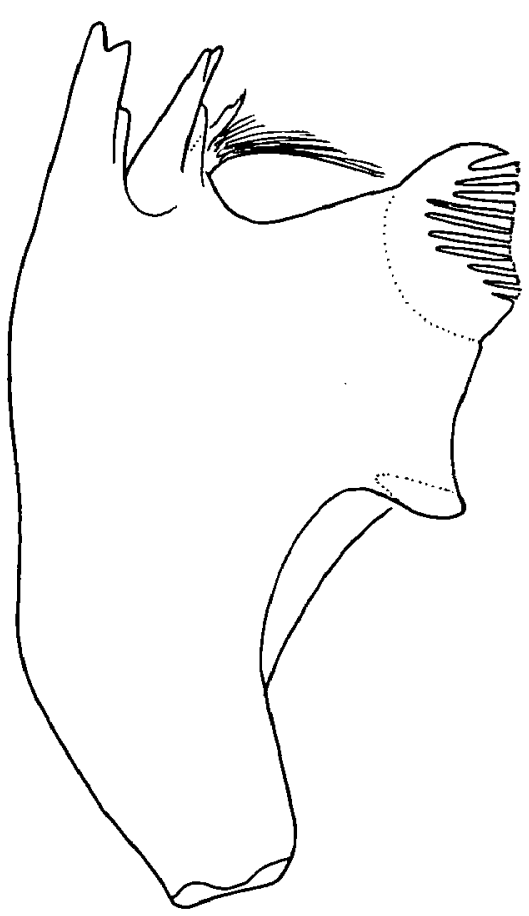

23

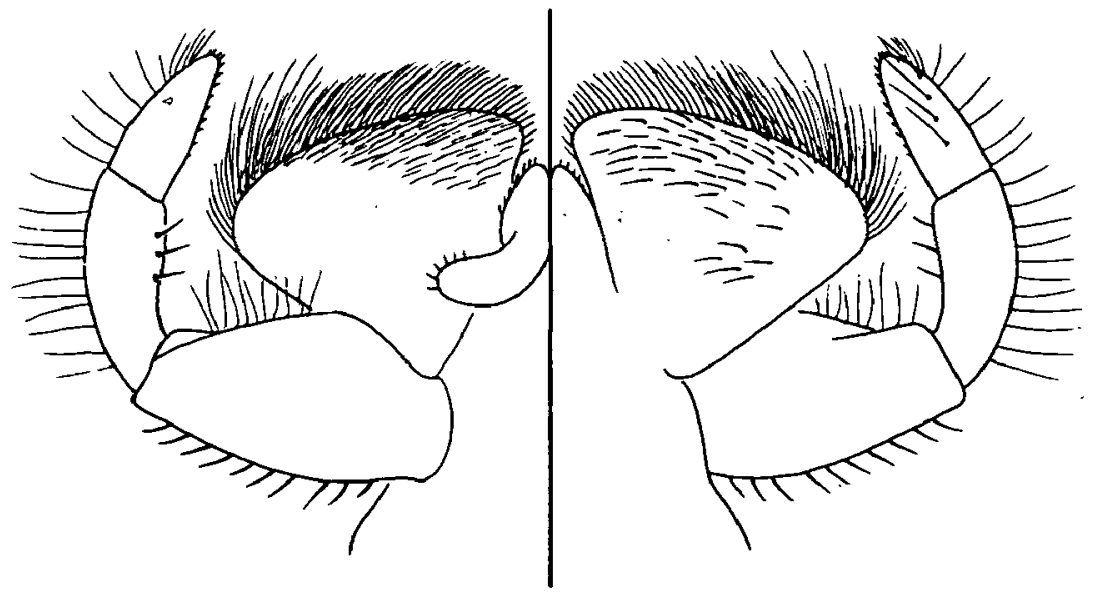

26

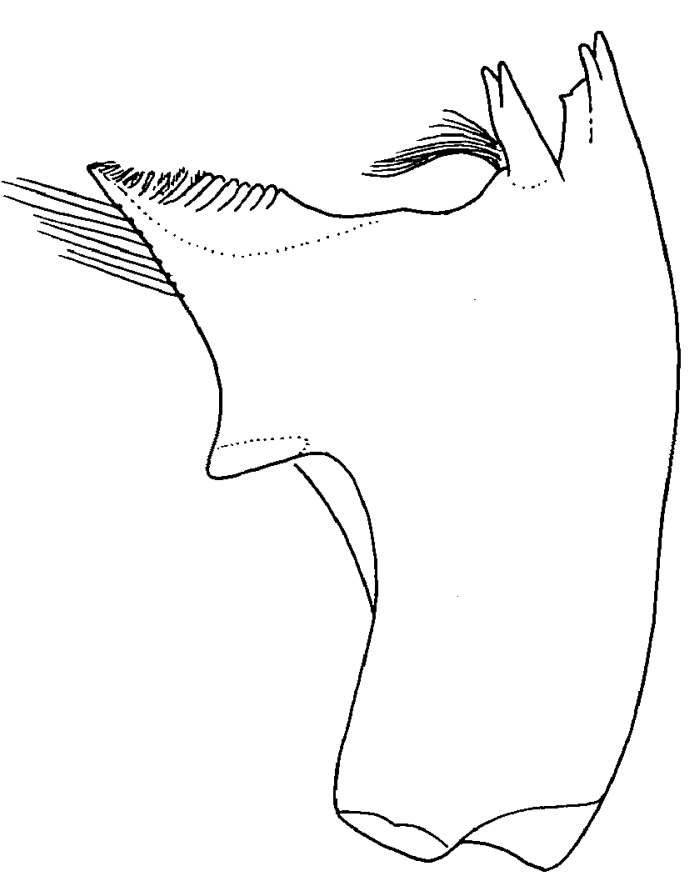

24

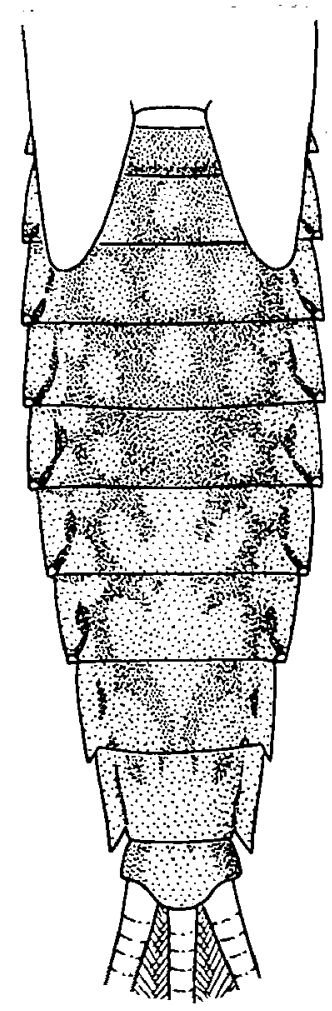

27

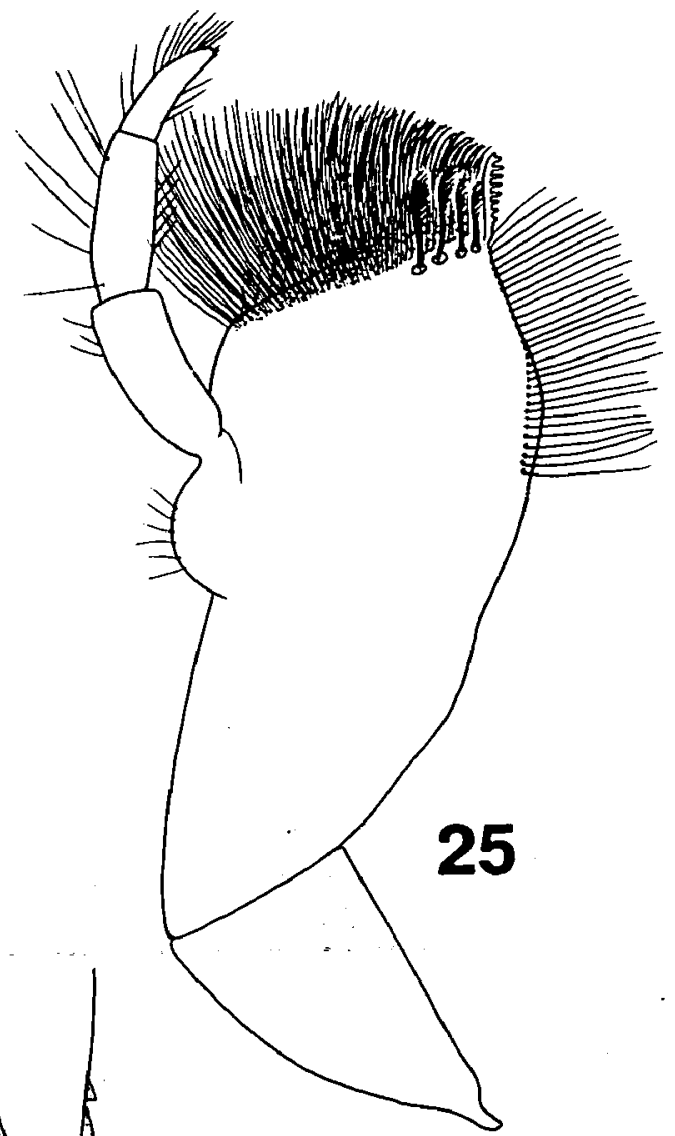

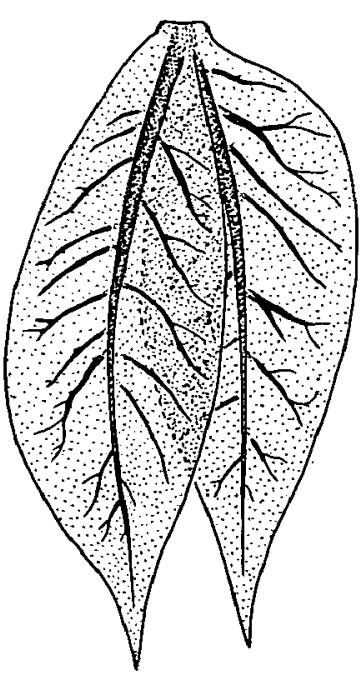

28

Fig. 21-28. Terpides diadema, n. sp., mature larva. $21:$ labrum (dorsal). $22:$ hypopharynx. $23:$ left mandible. $24:$ right mandible. $25:$ right maxilla. 26 : labium. 27 : abdomen (dorsal). 28 : gill 4.

Fig. 21-28. Terpides diadema, n. sp., larve au dernier stade. $21:$ labre (vue dorsale). 22 : hypopharynx. $23:$ mandibule gauche. $24:$ mandibule droite. $25:$ maxille droite. $26:$ labium. $27:$ abdomen (vue dorsale). $28: 4 \mathrm{e}$ branchie.Fig. $21-28$. Terpides diadema, n. sp., mature larva. 
merous fine, simple setae ; palps three segmented ; segment 1 robust, with many long, simple setae laterally, segment 2 more slender than segment 1 , with very fine, simple setae scattered along lateral margin, segment 3 pointed and less robust than preceding segments, with few very fine, simple setae laterally.

Thorax : Coloration pale yellow to pale brown. Pronotum and mesonotum sometimes with anterolateral black markings. Sterna pale, except for medial black ganglionic marks. Fore- and midfemora with numerous fine, simple setae dorsally, ventral margin and anterior face with short, simple setae and black apical markings ; foretibiae with numerous branched setae ventrally, dorsal margin with fine, long, simple setae, black markings' often present proximally and ventrally; tarsi bare except for the presence of scattered fine, long, simple setae ; tarsal claws with 8-12 denticles. Midtibiae similar to foretibiae, except for short, simple setae along anterior face and ventrally. Hindlegs similar to midlegs, except setation (especially on ventral margin) more numerous on all segments.

Abdomen : Coloration pale yellow to pale brown, with complex pattern (Fig. 29). Terga 1-3 black with large, sublateral, pale yellow circles or ovals ; terga 45 pale to pale yellow with anterolateral and lateral black marks ; terga 6-8 similar to terga $1-3$, except for medial pale to pale yellow line ; tergum 9 pale, with very small anterolateral black dots ; tergum 10 blackish posteriorly. All terga with sharp spines along posterior margin. Sterna pale to pale yellow, except for medial ganglionic black mark on seventh sternum. Gills (Fig. 30) tapering abruptly, translucent, well tracheated. Caudal filaments basally brown, turning pale distally ; medial region with every fourth joint brown.

\section{Material examined}

Holotype : Female larva, MEXICO, Hidalgo Sta., Metztlitlán, III-22-1977, Zapién, deposited at PERC. Paratypes: Twenty-eight female and 12 male larvae, same data as holotype, four female and three female larvae deposited at PERC, remaining larvae deposited at UNAM ; two female larvae, MEXICO, Morelos Sta., Río Yautepec, I-15-1987, R. Novelo-Gutiérrez, deposited at IEAC.

Additional material examined: Three female larvae, MEXICO, Morelos Sta., Jojutla, Vicente Aranda, Río Amacúzac, 800 m, I-15-1983, S. Ibáñez, deposited at IEAC. Three male and 18 female larvae, MEXICO, Morelos Sta., Río Venados, IX-10-1979, Zapién, deposited at UNAM.

\section{Etymology}

The specific epithet is a Latin word meaning extraordinary. It is a reference to the unusual abdominal color pattern of the larva.

\section{Discussion}

Allen and Brusca (1978) described their T. sp. B from material collected from Mexico. It is equivalent to the species described here. Its distinct larval abdominal color pattern (Fig. 29) should be sufficient to distinguish it from all other members of the genus. The abdominal coloration of T. eccentricus is not found in any of the known adults of Thraulodes, and therefore we conclude that it does not represent the unknown larva of any species previously named from adults.

\section{Thraulodes grandis, n. sp.}

\section{Mature larva}

Body : length $8.0-10.5 \mathrm{~mm}$. Caudal filaments : length $9.0-12.0 \mathrm{~mm}$. General coloration medium brown with pale yellow markings.

Head : Coloration brown. Bases of ocelli and antennae pale. Antennae pale brown to pale yellow-brown ; scapes and pedicels brown. Vertex with two opposed C-shaped brown marks ; posterior margin pale. Labrum suffused with black dorsally, with two long rows of simple setae above anteromedial emargination and with fine, simple setae scattered dorsally and marginally ; anteromedial emargination very shallow ; no denticles present on anteromedial emargination. Hypopharynx suffused with black on medial region of dorsal surface ; lingua with long, curved lateral processes, and medial emargination interrupted by medial hump ; superlinguae with numerous long, simple setae along exterior margin. Right mandible suffused with black dorsally ; row of fine, simple setae extending from middle portion of lateral margin to base of outer incisors ; basal and distal sets of incisors with three denticles. Left mandible same as right mandible. Maxillae suffused with black laterally ; galealacinia with very dense tuft of rust colored, simple setae and 15-18 long, pectinate setae submarginally on anterolateral area of ventral surface ; palps four segmented, with very long, fine simple setae scattered along lateral margin ; palp segment 1 very small, entirely suffused with black ; segment 2 basally suffused with black; segments 3 and 4 pale; segment 4 pointed, with numerous fine, simple setae distolaterally and medially. Labium with glossae and paraglossae covered with numerous fine, simple setae ; palps three segmented ; segment 1 robust, with many long, simple setae laterally, segment 2 more slender than segment 1 , with very fine, simple setae scattered along lateral margin, segment 3 pointed and less robust than preceding segments, with few very fine, simple setae laterally. 
Thorax : Coloration pale brown to medium brown. Pronotum with three pale anteromedial maculae, central macula elongate, lateral maculae round ; very lightly suffused with black anterolaterally; lateral margins pale ; pale medial triangle posteriorly. Mesonotum with various pale markings. Sterna pale brown. Pleura suffused with black. Forefemora basally white on anterior face, with two pale maculae on medial and subdistal regions ; short, robust, simple setae scattered over anterior face ; posterior face pale ; black stripe present distally on ventral margin ; dorsal margin with dense row of long, fine, simple setae and numerous robust, simple, brown setae of various lengths ; foretibiae brown, lightly suffused with black distally, with small, brown setae ventrally and long, fine setae dorsally ; foretarsi brown, lightly suffused with black, with fine, long, simple setae dorsally and ventrally. Midlegs similar to forelegs, except proximal black macula on posterior face of femora and long, fine, simple setae denser dorsally on tibiae. Hindlegs similar to midlegs, except dorsal margin of tibiae with two rows of small, dark brown, simple setae. Tarsal claws with seven to nine denticles.

Abdomen : Coloration brown, with pale yellow maculae (Fig. 31). Tergum 1 pale yellow to pale brown; tergum 2 medium brown, with two small black anterolateral maculae ; tergum 3 as tergum 2, except with faint posteromedial macula ; terga 4-7 with small black anterolateral maculae and pale yellow oval posteromedian marks ; terga 8-9 with pale yellow posteromedian oval marks ; tergum 10 brown; tergal lateral margins pale. Sterna pale. Gills (Fig. 32) tapering gradually, with black median tracheae, lightly suffused with black dots marginally. Caudal filaments basally brown, becoming pale distally.

\section{Material examined}

Holotype : Female larva, GUATEMALA, Izabal Prov., small stream in [tributary of?] Río Cahabón, nr Cahaboncito, I-4-1989, B. C. Kondratieff, deposited in PERC. Paratypes: Two female larvae, same data and deposition as holotype.

\section{Etymology}

The specific epithet is a Latin word meaning large. It is an allusion to the relatively large size of the species.

\section{Discussion}

The present specimens are described as a separate species on the basis of their general abdominal coloration and large size. The large pale yellow maculae on terga 4-8 (Fig. 31) will readily separate this species from the other known larvae of the genus.

\section{Thraulodes tenulineus, $\mathbf{n}$. sp.}

Thraulodes sp. D Allen and Brusca 1978 : 422.

Thraulodes arizonicus: Allen and Murvosh 1987 : 284 (misidentification).

\section{Mature larva}

Body : length 5.2-6.1 mm ; caudal filaments : length 9.0-11.0 mm. General coloration pale brown to pale yellow-brown.

Head : Coloration pale to pale yellow-brown. Area between ocelli with $\mathrm{V}$-shaped black marking. Turbinate eyes in male larvae pale yellow to yellow-black. Antennae pale, 2.0-2.3x length of head capsule. Clypeus pale to pale yellow-brown. Labrum lightly suffused with black dorsally, with two long rows of simple setae above anteromedial emargination and scattered fine, simple setae dorsally and marginally ; anteromedial emargination with two long denticles and one very small denticle. Hypopharynx lightly suffused with black ; lingua with long, curved lateral processes, medial emargination interrupted by medial hump ; superlinguae with numerous long, simple setae along exterior margin. Right mandible lightly suffused with black dorsally; row of fine, simple setae extending from middle portion of lateral margin to base of outer incisors; basal and distal sets of incisors with three denticles. Left mandible same as right mandible. Maxillae lightly suffused with black laterally ; galealacinia with very dense distal tuft of rust colored simple setae and 15-18 long, pectinate setae submarginally on anterolateral area of ventral surface ; palps four segmented, with very long, fine, simple setae scattered laterally; palp segment 1 very small, entirely suffused with black; segment 2 basally suffused with black; segments 3 and 4 pale ; segment 4 pointed, with numerous fine setae distolaterally. Labium with glossae and paraglossae covered with numerous fine, simple setae ; palps three segmented, segment 1 robust and with many long, simple setae laterally, segment 2 more slender than segment 1 , with fine, simple setae scattered laterally, segment 3 pointed and less robust than preceding segments, with some fine, simple setae laterally.

Thorax : Coloration pale to yellow brown, with no distinct color pattern. Pronotum sometimes with posteromedial pale triangle and very faint white markings. Sterna pale brown. Forefemora with numerous fine, simple setae dorsally, ventral margin and anterior face with short, simple setae, and with dark distoventral mark ; foretibiae with numerous branched setae ventrally and fine, long, simple setae dorsally, black band sometimes present distally ; tarsi bare except for the 


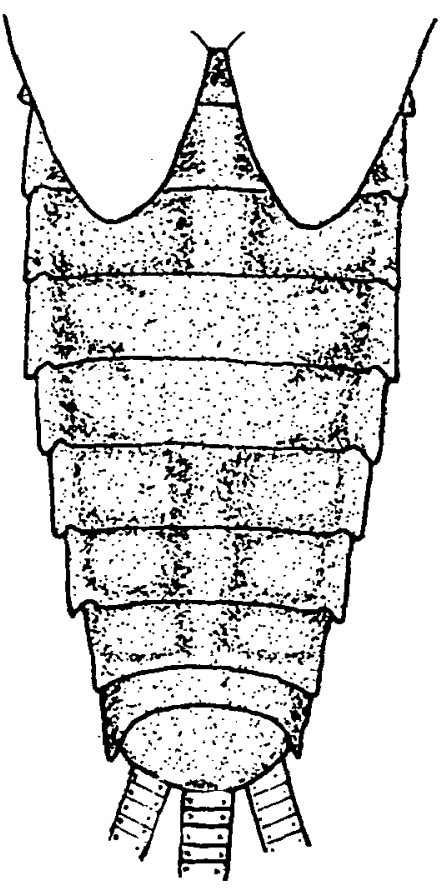

29

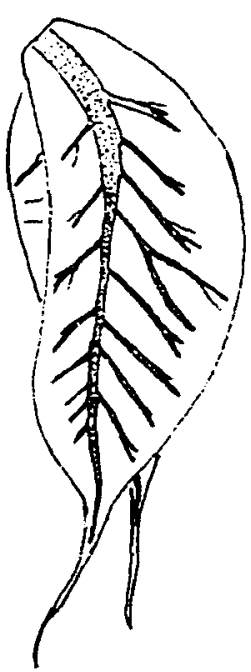

30

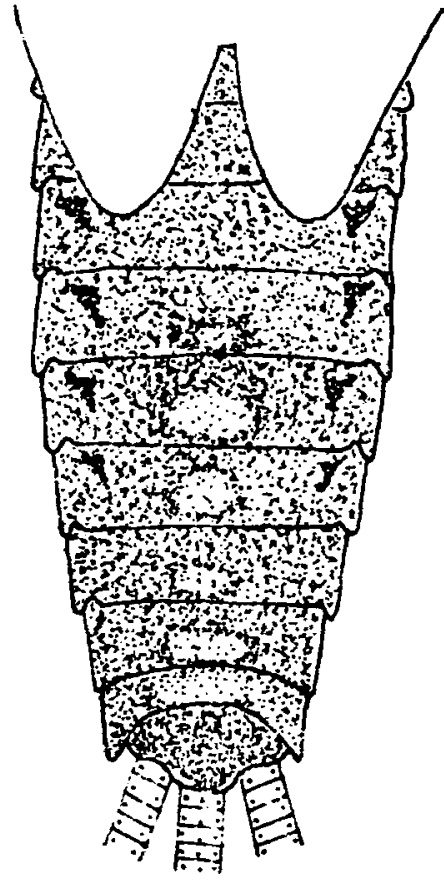

31

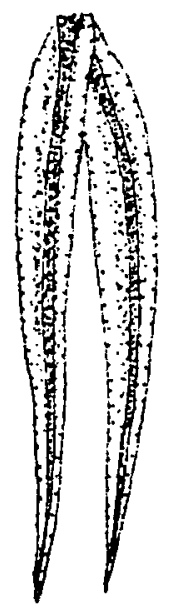

32

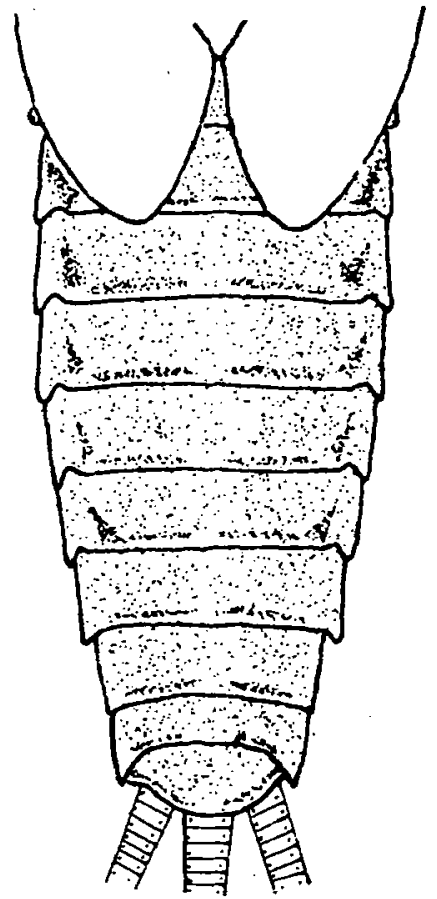

33

Fig. 29-33. Thraulodes spp., mature larvae. $29:$ T. eccentricus, n. sp., abdomen (dorsal). $30:$ T. eccentricus, n. sp., gill $4.31:$ T. grandis, n. sp., abdomen (dorsal). $32:$ T. grandis, n. sp., gill 4. $33:$ T. tenulineus, n. sp., abdomen (dorsal).

Fig. 29-33. Thraulodes spp., larves au dernier stade.

$29:$ T. eccentricus, n. sp., abdomen (vue dorsale). $30:$ T. eccentricus, n. sp., 4e branchie. $31:$ T. grandis, n. sp., abdomen (vue dorsale). $32: T$. grandis, n. sp., 4 e branchie. $33:$ T. tenulineus, n. sp., abdomen (vue dorsale).

presence of scattered fine, long, simple setae ; tarsal claws with five to seven denticles. Midfemora similar to forefemora ; midtibiae similar to foretibiae, except for short, simple setae on anterior face and ventrally. Hindlegs similar to midlegs, except setation (especially on ventral margin) more numerous on all segments.

Abdomen : Coloration pale brown to pale yellowbrown (Fig. 33). Terga 1-10 with thin black posterior line ; lines on middle segments often broken medially and appearing as two sublateral lines. Sterna pale. Gills tapering gradually, slender, translucent, with no lateral tracheation. Caudal filaments basally brown to yellow-brown, becoming paler towards distal end ; every fourth joint dark brown in medial region.

\section{Material examined}

Holotype : Female larva, MEXICO, Morelos Sta., Jojutla, Vicente Aranda, Río Amacúzac, 800 m, III-261983, S. Ibáñez, deposited at PERC. Paratypes : Seventeen female and one male larvae, same data as holotype, 13 female larvae deposited at IEAC, four female and male larvae deposited at PERC ; two male and two female larvae, I-14-83, deposited at IEAC ; two female and one male larvae, same data, I-15-83, deposited at IEAC. Additional material examined: Three female lar- vae, MEXICO, Morelos Sta., Jojutla, Vicente Aranda, Río Amacúzac, 800 m, III-26-1983, G. Rodríguez, deposited at IEAC ; three female and one male larvae, same data, XII-11-82, G. Cardoso ; two female larvae, same data, XII-21-81, R. Arce, deposited at IEAC ; six female and one male larvae, MEXICO, Oaxaca Sta., Dominguillo, III-8-1978, Zapién, deposited at UNAM.

\section{Etymology}

The specific epithet is a an arbitrary combination of letters based on the Latin words tenuis (thin) and linea (line). It alludes to the thin lines of the posterior margins of the abdominal segments.

\section{Discussion}

Allen and Brusca (1978) described T. sp. D from larvae collected from Honduras and Mexico. Allen and Murvosh (1987) noted that these had a black apical band on the foretibiae, and on that basis considered them to be the larvae of $T$. arizonicus. Six species of Thraulodes known from adults only ( $T$. irretitus, $T$. lepidus, $T$. prolongatus, $T$. spangleri, and $T$. valens) similarly have a black or dark apical band on the foretibiae, whereas four species known from type material only ( $T$. brunneus, T. hilaroides, T. lunatus, and $T$. 
mexicanus) lack the forelegs and thus the presence or absence of this band cannot be ascertained. Therefore, we do not recognize Allen and Murvosh's (1987) assignment of $T$. sp. D to $T$. arizonicus, and consider $T$. sp. $\mathrm{D}$ a new species.

\section{Traverella holzenthali, n. sp.}

\section{Mature larva}

Body : length $8.0-11.8 \mathrm{~mm}$; caudal filaments : length $11.0-14.0 \mathrm{~mm}$. General coloration dark brown.

Head : Coloration dark brown, with lateral dark yellow-brown marks on clypeus, whitish areas at bases of antennae and ocelli, and yellow-brown spots on vertex (Fig. 34). Antennae medium brown, paler distally, 2.5$3.0 x$ longer than head capsule. Small triangular frontoclypeal process extending forward (Fig. 34). Clypeus convex on lateral margins. Labrum (Fig. 35) medium brown to dark brown, with row of 20-25 long, simple setae on each side and small, simple setae scattered over dorsal surface ; small notch present anteromedially. Hypopharynx (Fig. 36) with anterior margin of lingua broadly cleft and with well-developed lateral processes ; superlinguae with numerous long, simple setae anteriorly and laterally. Left mandible (Fig. 37) medium brown to dark brown, with outer margin sharply curved, almost forming right angle ; both sets of incisors with three denticles; prostheca with tuft of setae almost extending as far as mola. Right mandible (Fig. 38) as left mandible, except basal set of incisors with three denticles and distal set with two denticles. Maxillae (Fig. 39) with palps three segmented; palp segment 1 short, near $1 / 3$ length of segment 2 ; segment 2 long and slender, bare ; segment 3 pointed, with five rows of long, simple setae ; galealaciniae with two or three rows of long, fine setae, with pointed process apically on medial margin and row of long, simple setae medially. Labium (Fig. 40) with palps three segmented, segments subequal in length; palp segment 1 with 25 35 short, simple setae medially ; segment 2 with 20-25 long, simple setae medially; segment 3 pointed, with numerous short, simple setae, móstly medially ; glossae pyramidal from ventral aspect, round from dorsal aspect, with numerous short, simple setae scattered over surface ; paraglossae broadly ovate, with numerous simple setae marginally.

Thorax : Coloration dark yellow-brown, with no distinct pattern. Pronotum with short, simple setae anterolaterally ; robust anterolateral setae absent. Sterna yellow-brown to gray-brown. Femora whitish basally, yellow-brown medially, suffused with black distally, with long and short, robust, simple subdistal setae dorsally, and with numerous short, stout, simple setae ven- trally. Tibiae dark yellow-brown, with very fine, long, simple setae dorsally and robust, simple setae of medium length ventrally. Tarsi pale yellow-brown, whitish distally; one robust, simple subapical seta ventrally ; numerous fine, long, simple setae dorsally ; tarsal claws with six to eight minute, basal denticles and six to seven small distal denticles.

Abdomen : Coloration very dark yellow-brown, with no distinct pattern. Terga with alternating short and long, sharp spines along posterior margin. Sterna 1-7 pale yellow-brown to medium yellow-brown, 8-9 dark yellow-brown to medium brown. Gills purplish black. Caudal filaments dark brown basally, turning dark yellow-brown medially, becoming paler distally ; short setae on each joint.

\section{Material examined}

Holotype : Female larva, COSTA RICA, Guanacaste Prov., Río Los Ahogados, $10.865^{\circ} \mathrm{N} / 85.423^{\circ} \mathrm{W}, 470$ m, III-7-1986, Holzenthal and Fasth, deposited at FAMU. Paratypes : Two female larvae, same data as holotype, deposited at FAMU and PERC.

\section{Etymology}

We name this species after Ralph W. Holzenthal, who collected the type material.

\section{Discussion}

Traverella holzenthali is similar to $T$. albertana and they may represent sister species. It differs from $T$. albertana in its very dark coloration, somewhat more developed frontoclypeal process (Fig. 34), and the lack of robust anterolateral setae on the pronotum.

\section{Traverella longifrons, $\mathbf{n}$. sp.}

Traverella sp. B Allen 1973 : 1294.

\section{Mature larva}

Body : length 7.0-8.5 mm; caudal filaments: length 7.0-8.0 mm. General body coloration pale yellowbrown to medium brown.

Head : Coloration pale yellow-brown to medium brown ; frons with median macula and pale maculae below compound eyes (Fig. 41). Antennae pale brown, 2.5-3.0x longer than head capsule. Large triangular frontoclypeal process extending forward (Fig. 41). Clypeus convex on lateral margins. Labrum (as in Fig. 35) medium brown to dark brown, with row of 20-25 long, simple setae on each side and small, simple setae scattered over dorsal surface ; small notch present anteromedially. Hypopharynx (as in Fig. 36) with anterior margin of lingua broadly cleft and well-developed lateral processes ; superlinguae with numerous long, simple setae anteriorly and laterally. Left mandible (as 
in Fig. 37) medium brown to dark brown, with outer margin sharply curved, almost forming right angle ; both sets of incisors with three denticles ; prostheca with tuft of setae almost extending as far as mola. Right mandible (as in Fig. 38) as left mandible, except basal set of incisors with three denticles and distal set with two denticles. Maxillae (as in Fig. 39) with palps three segmented ; palp segment 1 short, near 1/3 length of segment 2 ; segment 2 long and slender, bare ; segment 3 pointed, with five rows of long, simple setae ; galealaciniae with two or three rows of long, fine setae, with pointed process apically on medial margin and row of long, simple setae medially. Labium (as in Fig. 40) with palps three segmented, segments subequal in length ; palp segment 1 with 25-35 short, simple setae medially; segment 2 with 20-25 long, simple setae medially; segment 3 pointed, with numerous short, simple setae, particularly medially; glossae pyramidal from ventral aspect, round from dorsal aspect, with numerous short, simple setae scattered over surface ; paraglossae broadly ovate, with numerous simple setae marginally.

Thorax : Coloration pale yellow-brown to medium brown, with no distinct pattern. Pronotum with short, fine and short, robust, simple setae anterolaterally. Sterna yellow-brown. Femora pale basally, suffused with black distally ; long and short, robust, simple subdistal setae dorsally ; numerous short, stout, simple setae dorsally. Tibiae yellow-brown, with long, fine, simple setae dorsally and robust, simple setae of medium length ventrally. Tarsi pale, with four to five short, robust, simple setae ventrally ; tarsal claws with seven to ten minute basal denticles and four to five small distal denticles.

Abdomen : Coloration pale yellow-brown to medium brown. Terga with sharp spines and fine setae posteriorly. Sterna pale yellow-brown. Gills purplish. Caudal filaments dark brown basally, becoming pale distally; short setae on each joint.

\section{Material examined}

Holotype: Male larva, COSTA RICA, Heredia Prov., Río Sarapiquí, $7 \mathrm{~km}$ W of Puerto Viejo, $10.452^{\circ} \mathrm{N} / 84.067^{\circ} \mathrm{W}, 50 \mathrm{~m}, \mathrm{II}-11-1986$, Morse and Fasth, deposited at FAMU. Paratypes : Two male larvae and one female larva, COSTA RICA, Guanacaste Prov., Río Tenorio at Finca La Pacífica, E of Panamerican Hwy, II-2-1969, W. P. McCafferty, deposited at PERC ; same data, II-8-11-1969, deposited at PERC ; two male larvae and one female larva, Reserva Biológica Hitoy-Cerere, Río Cerere, $9.671^{\circ} \mathrm{N} / 83.028^{\circ} \mathrm{W}, 90$ m, III-23-24-1987, Holzenthal, Hamilton, and Heyn ; three male and two female larvae, COSTA RICA, Pun- tarenas Prov., Río Ceibo, Rt $2 \mathrm{nr} 6 \mathrm{~km} \mathrm{~W}$ of Rd to Buenos Aires, $9.149^{\circ} \mathrm{N} / 83.377^{\circ} \mathrm{W}, 250 \mathrm{~m}, \mathrm{II}-20-86$, Holzenthal, Morse, and Fasth, deposited at FAMU.

Additional material examined: Two male and ten female larvae, COSTA RICA, Guanacaste Prov., Río Tenorio at Finca La Pacífica, E of Panamerican Hwy, II2-1969, W. P. McCafferty, deposited at PERC ; four female larvae, same data, II-2-8-1969, deposited at PERC.

\section{Etymology}

The specific epithet is an arbitrary combination of letters alluding to the elongate triangular frontoclypeal process of the larva.

\section{Discussion}

Allen (1973) described this species as Traverella sp. B from material collected from San Luis Potosí and Veracruz. The Costa Rican records indicate that $T$. longifrons is a widespread species in Mexico and Central America. The species is differentiated from other larvae of the genus by the distinct long, triangular frontoclypeal process (Fig. 41).

\section{Traverella promifrons, $\mathbf{n}$. sp.}

Traverella sp. C Allen 1973 : 1294.

\section{Mature larva}

Body : length 7.0-8.5 mm ; caudal filaments : length $7.0-8.0 \mathrm{~mm}$. General body coloration pale brown to medium brown.

Head : Coloration pale brown to medium brown ; frons with median macula and pale maculae below compound eyes (Fig. 42). Compound eyes in males yellow-black. Antennae pale brown, 2.0-2.5x longer than head capsule. Triangular frontoclypeal process extending upward (Fig. 42). Clypeus convex on lateral margins. Labrum (as in Fig. 35) medium brown to dark brown, with row of 20-25 long, simple setae on each side and small, simple setae scattered over dorsal surface ; small notch present anteromedially: Hypopharynx (as in Fig. 36) with anterior margin of lingua broadly cleft and well-developed lateral processes ; superlinguae with numerous long, simple setae anteriorly and laterally. Left mandible (as in Fig. 37) medium brown to dark brown, with outer margin sharply curved, almost forming right angle ; both sets of incisors with three denticles ; prostheca with tuft of setae almost extending as far as mola. Right mandible (as in Fig. 38) as left mandible, except basal set of incisors with three denticles and distal set with two denticles. Maxillae (as in Fig. 39) with palps three segmented ; palp segment 1 short, near $1 / 3$ length of segment 2 ; 

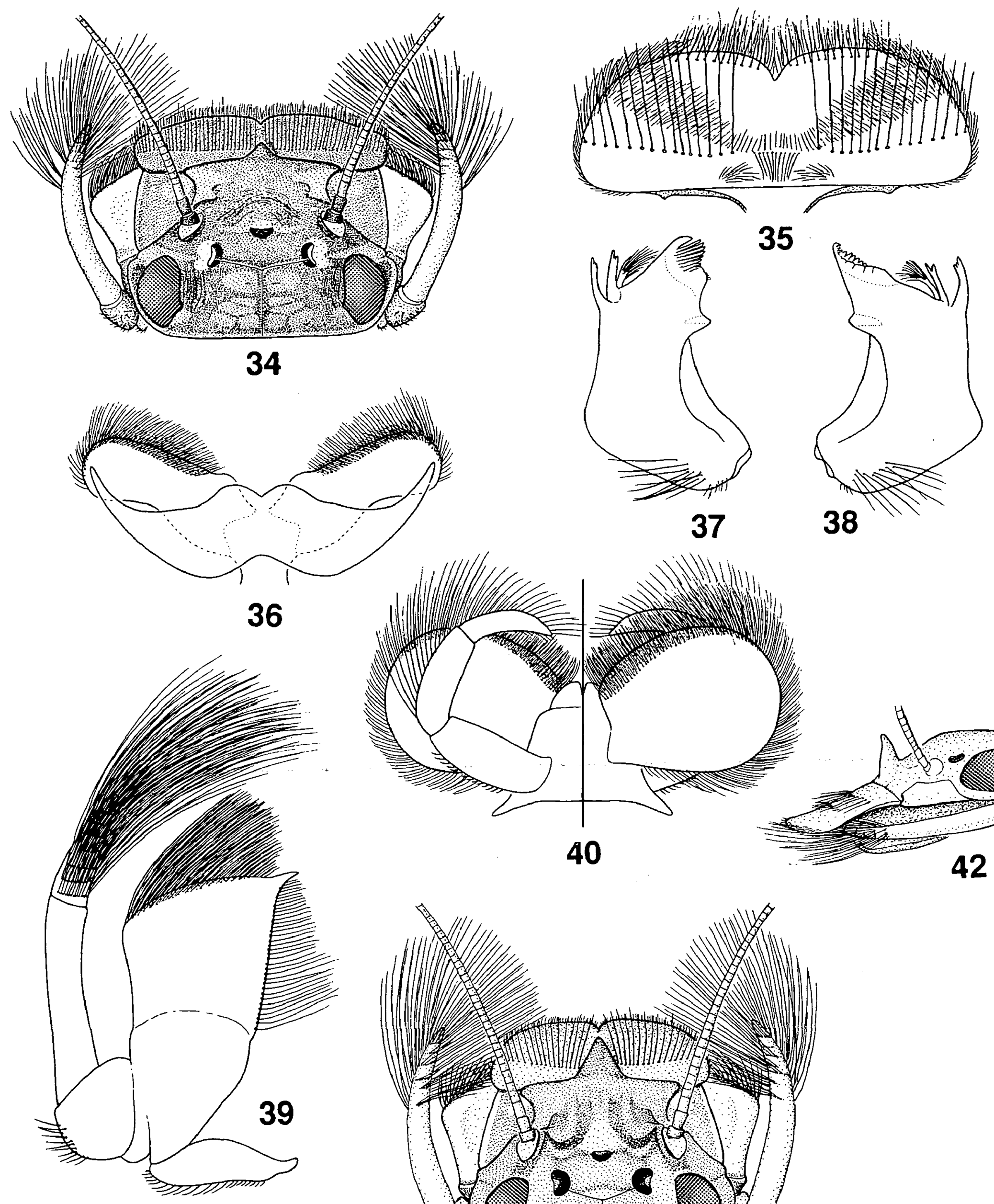

40

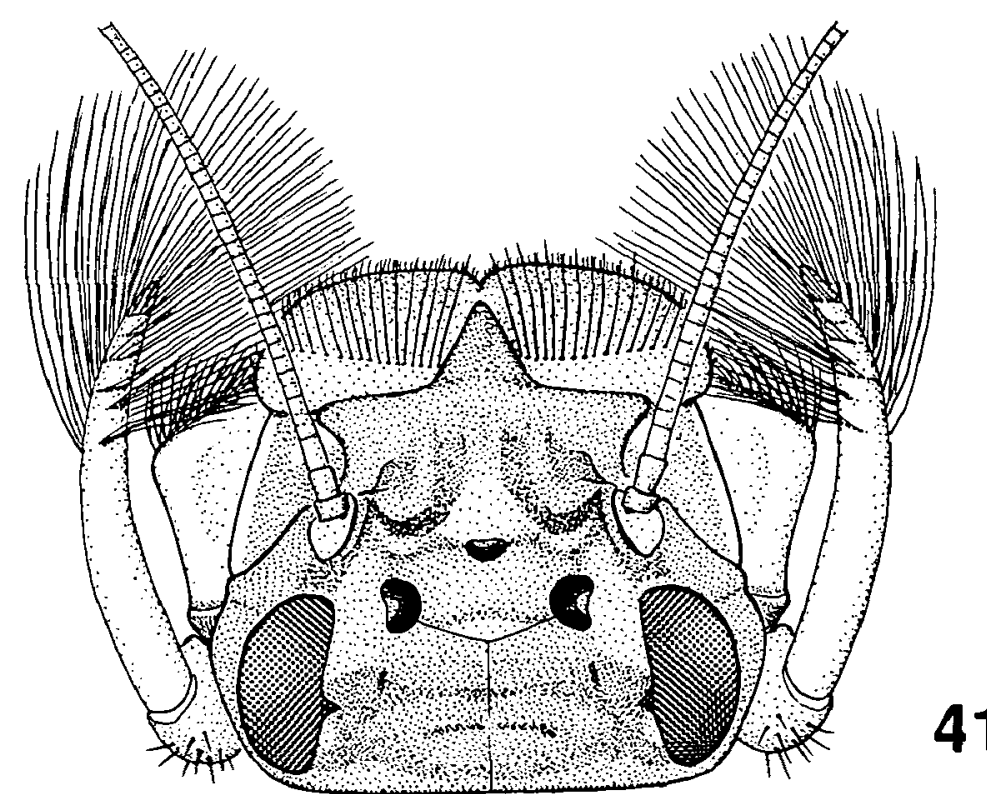

Fig. 34-42. Traverella spp., mature larvae. $34: T$. holzenthali, n. sp., head (dorsal). $35: T$. holzenthali, n. sp., labrum (dorsal). $36: T$. holzenthali, n. sp., hypopharynx. $37: T$. holzenthali, n. sp., left mandible. $38: T$. holzenthali, n. sp., right mandible. $39:$ T. holzenthali, n. sp., right maxilla. 40 : T. holzenthali, n. sp., labium. 41 : T. longifrons, n. sp., head (dorsal). $42:$ T. promifrons, n. sp., head (dorsal).

Fig. 34-42. Traverella spp., larves au dernier stade. $34:$ T. holzenthali, n. sp., tête (vue dorsale). $35:$ T. holzenthali, n. sp., labre (vue dorsale). $36:$. holzenthali, n. sp., hypopharynx. $37:$ T. holzenthali, n. sp., mandibule gauche. $38: T$. holzenthali, n. sp., mandibule droite. $39:$ T. holzenthali, n. sp., maxille droite. $40: T$. holzenthali, n. sp., labium. $41: T$. longifrons, n. sp., tête (vue dorsale). $42: T$. promifrons, n. sp., tête (vue dorsale). 
segment 2 long and slender, bare ; segment 3 pointed, with five rows of long, simple setae ; galealaciniae with two or three rows of long, fine setae, with pointed process apically on medial margin and row of long, simple setae medially. Labium (as in Fig. 40) with palps three segmented, segments subequal in length ; palp segment 1 with 25-35 short, simple setae medially ; segment 2 with 20-25 long, simple setae medially ; segment 3 pointed, with numerous short, simple setae, particularly medially ; glossae pyramidal from ventral aspect, round from dorsal aspect, with numerous short, simple setae scattered over surface ; paraglossae broadly ovate, with numerous simple setae marginally.

Thorax : Coloration pale brown to medium brown, with no distinct pattern. Pronotum with short, fine and short, robust, simple setae anterolaterally. Sterna yellow-brown. Femora pale basally, suffused with black distally; long and short, robust simple subdistal setae dorsally; numerous short, stout simple setae ventrally. Tibiae yellow-brown, with very fine, long, simple setae dorsally and robust setae of medium length ventrally. Tarsi pale, with four to five short, robust setae ventrally ; tarsal claws with seven to nine minute basal denticles and four to five irregular distal denticles.

Abdomen : Coloration pale yellow-brown. Terga often with pale brown medial streak; and with sharp spines posteriorly. Gills purplish. Caudal filaments dark brown basally, becoming pale distally ; short setae on each joint.

\section{Material examined}

Holotype : Male larva, BELIZE, Cayo Prov., Roaring Creek, riffle, VI-20-1974, V. Resh, deposited at PERC. Paratypes: Three male and three female larvae, COSTA RICA, Guanacaste Prov., Río Tenorio at Finca La Pacífica, E of Panamerican Hwy., II-8-111969, W. P. McCafferty, deposited at PERC.

Additional material examined: Two female larvae, same data as holotype, deposited at PERC ; one female larva, BELIZE, Mopán-Melchor, VI-27-74, V. Resh, deposited at PERC ; one female larva, same data as paratypes, deposited at PERC.

\section{Etymology}

The specific epithet is an arbitrary combination of letters alluding to the prominent, upwardly directed frontoclypeal process.

\section{Discussion}

Allen (1973) adequately characterized the larva of this species as Traverella sp. C from material collected from Honduras and Mexico. Larvae of $T$. promifrons can be differentiated from other known species of Traverella by its distinct, upwardly oriented frontoclypeal process (Fig. 42).

\section{Acknowledgements}

We thank the following individuals for the loan, donation, or collection of material used in this study: J. Bueno Soria (Universidad Nacional Autónoma de México, México, D. F.), R. W. Flowers (Florida A\&M University, Tallahassee), R. W. Holzenthal (University of Minnesota, St. Paul), B. C. Kondratieff (Colorado State University, Fort Collins), R. Novelo Gutiérrez (Instituto de Ecología, A. C., Veracruz, México), and M. L. Pescador (Florida A\&M University, Tallahassee). We also thank A. V. Provonsha (Purdue University, West Lafayette, Indiana) for the line drawings. This paper has been assigned Purdue Agricultural Research Program Journal No. 14397

\section{References}

Allen (R. K.). 1973, - Generic revisions of mayfly nymphs. 1. Traverella in North and Central America (Leptophlebiidae). Ann. Entomol. Soc. Am., 66 : 1287-1295.

Allen (R. K.) \& Brusca (R. C). 1978. - Generic revisions of mayfly nymphs. II. Thraulodes in North and Central America (Leptophlebiidae). Can. Entomol., $110: 413-433$.

Allen (R. K.) \& Murvosh (C. M.). 1987. - Leptophlebiidae of the southwestern United States and northwestern Mexico (Insecta : Ephemeroptera). Great Basin Natur., 47 : 283-286.

Davis (J. R.). 1987. - A new species of Farrodes (Ephemeroptera Leptophlebiidae : Atalophlebiidae) from southern Texas. Proc. Entomol. Soc. Wash., 89 : 407-416.

Edmunds (G. F., Jr.), Jensen (S. L.), \& Berner (L.). 1976. - The mayflies of North and Central America. Univ. Minnesota Press, Minneapolis : $330 \mathrm{p}$.

Faber (D.). 1993. - Environment under fire: imperialism and the ecological crisis in Central America. Month. Rev. Press, N. Y. : $301 \mathrm{p}$.

Flowers (R. W.). 1991. - Diversity of stream-living insects in northwestern Panamá. J. N. Am. Benthol. Soc., $10: 322-334$.

Flowers (R. W.). 1992. - Review of the genera of mayflies of Panama, with checklist of Panamanian and Costa Rican species. Pp. 37-51. In : Insects of Panama and Mesoamerica, D. Quintero and A. Aiello (eds.). Oxford University Press, Oxford.

McCafferty, (W. P.), Flowers (R. W.), \& Waltz (R. D.). 1992. - The biogeography of Mesoamerican mayflies : 173-193. In : Biogeography of Mesoamerica : proceedings of a symposium, S. P. Darwin and A. L. Welden (eds.). Tulane Univ. Stud. Zool. Bot., Suppl. Publ., 1.

Peters (W. L.). 1971. - A revision of the Leptophlebiidae of the West Indies (Ephemeroptera). Smith. Contr. Zool., 62 : 1-48.

Peters (W. L.). 1988. - Origins of the North American Ephemeroptera fauna, especially the Leptophlebiidae. Mem. Entomol. Soc. Can., 144 : 13-24.

Wheeler (Q. D.). 1990. - Insect diversity and cladistic constraints. Ann. Entomol. Soc. Am., 83 : 1032-1047. 